\title{
A Study on removal of Methylene Blue dye by photo catalysis integrated with
} nanofiltration using statistical and experimental approaches

\section{Naresh Yadav ${ }^{1,2}$, K. Anand Kishore ${ }^{1}$, Devendra Saroj²}

1-Department of Chemical Engineering, National Institute of Technology Warangal

2- Department of Civil and Environmental Engineering, University of Surrey, Guildford, United Kingdom

\begin{abstract}
In this work, the removal of Methylene Blue dye from the synthetic textile effluent has been investigated using a hybrid system (photocatalysis and nanofiltration). The Commercial $\mathrm{ZnO}$ powder was used as a catalyst in the photocatalytic operation. Response surface methodology (RSM) was employed to optimize the various operating parameters such as $\mathrm{pH}$, catalyst loading and time duration and this optimization has enhanced the decolorization efficiencies. The results were compared and contrasted with the individual as well as the combined systems at optimized conditions. The results indicate that the photocatalysis process alone has resulted in $33 \%$ of dye decolorization and $26.5 \%$ of total organic carbon (TOC) removal, while the individual ceramic nanoflitration system has yielded $43 \%$ of decolorization and $35.03 \%$ TOC removal. About $94 \%$ of the dye were decolorized, and $70 \%$ of TOC was removed in 94.23 minutes of operation by the hybrid system at optimized initial operating conditions.
\end{abstract}

\section{Keywords:}

Photocatalysis, Nanofiltration, Wastewater treatment, TOC removal, Decolorization, Hybrid system.

Corresponding author

Naresh Yadav

d.nareshyadav1989@gmail.com

To cite this article: D. Naresh Yadav, K. Anand Kishore \& Devendra Saroj (2020): A Study on removal of Methylene Blue dye by photo catalysis integrated with nanofiltration using statistical and experimental approaches, Environmental Technology, DOI: 10.1080/09593330.2020.1720303

https://doi.org/10.1080/09593330.2020.1720303 


\section{Introduction}

Photocatalytic oxidation has been being studied well for many decades as it is an advanced oxidation technology for reducing water pollution. Photocatalysis oxidizes and degrades various recalcitrant organic and inorganic pollutants present in the aqueous media, and it was investigated over a wide range of non-biodegradable organic pollutants for degradation and converting into less harmful intermediates. Due to its various advantages, photocatalytic reactors are in utilization on pilot or commercial scale for purification of recalcitrant industrial wastewaters [1-4]. Photocatalysis is classified into two distinct ways namely; homogenous and heterogeneous. In homogeneous photocatalysis, the catalyst will be in homogenous state and hence it is difficult to retrieve the catalyst after the water treatment. Whereas, it is easy to separate and reuse the catalyst in case of heterogeneous photocatalysis due to suspended or immobilized form. Saikia et al.[5] synthesized different morphologies of $\mathrm{ZnO}$ nanomaterials by distinct methods. The activity of the synthesized catalysts like flowershaped homocentric pencil-like $\mathrm{ZnO}$ nanorod bundles and $\mathrm{ZnO}$ nanoparticles were investigated under solar light. They found that these nanomaterials exhibit excellent photocatalytic degradation of malachite green dye. El-Kemary et al. [6] have synthesized nanostructured $\mathrm{ZnO}$ semiconductor with $2.1 \mathrm{~nm}$ diameter by employing chemical precipitation process. The synthesized $\mathrm{ZnO}$ nanoparticles have been used for the ciprofloxacin drug degradation in aqueous solutions at distinct $\mathrm{pH}$ values under UV light irradiation. They found that $\mathrm{pH} 7.0$ and 10.0 had shown effective photocatalytic property for the degradation of ciprofloxacin, whereas ineffective at $\mathrm{pH} 4.0$. After $60 \mathrm{~min}$ of operation, maximum degradation efficiency $(50 \%)$ of the drug was noticed at $\mathrm{pH}$ 10.0. Photo degradation in combination with membrane methods may have a better pollutant removal efficiency due to its retaining capacity towards the pollutants.

The larger size of organic pollutants in wastewater can reinstate by microspores that are present in the membrane. Generally, the membrane-based separation has compact in footprint, consumes lower energy for separation and easy operation [5]. The concentration polarization of retentate organic pollutants onto the membrane surface due to adsorption and precipitation generally resultants in fouling and reduces the efficiency of membrane separation [7-8]. This is the very common phenomenon observed in the case of both polymeric and ceramic membranes. Few researchers have confirmed that fouling issue results in the reduction in the membrane processes by combining advanced oxidation process with 
membrane separation [9][10]. The ceramic membrane rejects the degraded pollutants through partial oxidation along with the photocatalyst.

Cui et al.[11] studied the hybrid system (Photocatalysis and membrane separation) for the treatment of wastewater. In this work, the authors have reported that the combination of photocatalysis with the membrane-based filtration on a single set of unit shows many advantages in terms of lower footprint, maintenance, investment etc.[12]. $\mathrm{TiO}_{2}$ deposited on the surface of the membrane, and its membrane pores lead to the membrane fouling. It was observed that in combined technique of photocatalysis and membrane filtration system developed by Yang et al and Rajeswari et al.[13], the $\mathrm{TiO}_{2}$ photocatalyst has been in the suspended form, and they have studied the removal of carbaryl, a carbamate pesticide using ozonation $\left(\mathrm{O}_{3}\right)$, photolytic ozonation $\left(\mathrm{O}_{3} / \mathrm{UV}\right)$, and photocatalysis $\left(\mathrm{TiO}_{2} / \mathrm{UV}\right)$. They observed that Photocatalysis combined with ozonation process $\left(\mathrm{TiO}_{2} / \mathrm{UV} / \mathrm{O}_{3}\right)$ resulted $92 \%$ of chemical oxygen demand (COD) reduction at $\mathrm{pH} 6.0$ with $0.28 \mathrm{~g} / \mathrm{h}$ of ozone and $1 \mathrm{~g} / \mathrm{L} \mathrm{of} \mathrm{TiO}_{2}$ in 180 $\min$.

Few studies are available on fouling in membrane filtration as well as the possible measures for the prevention of fouling. Zahrim et al.[14] have published a review on the wastewater treatment using combination of coagulation and nanofiltration. In this work, the authors had observed minimal membrane fouling, drastic reduction in COD and color when the flocculent aid was added before the operation. Damodar et al.[15] have investigated purging of reactive black 5 (RB5) dye from aqueous media using microfiltration membrane [polytetrafluoroethylene (PTFE) MF membrane module] with a lab-scale photocatalytic slurry reactor. Their studies have shown that with combined approach 82-100\% decolorization, $45-93 \%$ TOC removal, and 50-85\% of COD removal was achieved. Damszel et al.[16] have studied Photocatalysis with immobilized catalyst bed/Nanofiltation and photocatalysis in suspension/UF/MD for the separation of azo dyes such as acid red 18, direct green 99 and acid yellow 36 from aqueous stream. Berberidou et al.[17] used combined system of photocatalysis and reverse osmosis filtration/nanofiltration to achieve a complete decolorization of reactive black 5 from synthetic dye effluent. They concluded that the organic content was reduced to more than $95 \%$ and the salinity can be obtained using the proposed hybrid system. Mozia et al.[18] have studied decolorization of acid red 18 dyes from aqueous media using two-hybrid approaches such as photocatalysis, ultrafiltration and photocatalytic membrane distillation. Among different photocatalysts, zinc oxide $(\mathrm{ZnO})$ is widely used as an excellent photocatalytic material for the purification of various wastewater since it exhibits high photocatalytic performance [19-23] in comparison to other metal oxides 
including $\mathrm{TiO}_{2}$ [24][25]. Hence, in this work $\mathrm{ZnO}$ was used as a photocatalyst for the decolorization and degradation of MB dye.

Experimental design methods are very much convenient and can be used to optimize the initial operating parameters. One such important experimental design method is the Response Surface Methodology (RSM). The RSM's major purpose is to optimize the response surface of the initial inputs. It investigates the connection between various input variables and output variables. Several steps are involved in RSM's design mechanism. It includes a) Conducting set of experiments for a good response of interest. b) Development of second-order mathematical model c) Estimation of favorable initial parameters with the least and the most output value of the conducted experimental data and d) Representation of operating conditions in two and three-dimensional graphs. RSM can be used to determine the interaction, quadratic and the linear effects of the parameters and also for the response of a predictive model [26][27].

The present work explores the efficiency of the combined operation of photocatalytic oxidation and nanofiltration for the decolorization and degradation of MB dye. As many of the works have dealt with the use of polymeric MF membranes in conjunction with photocatalysis, this work made an important contribution towards the combined operation of photocatalysis and ceramic nanofiltration membranes. The individual and the combined effect of photocatalysis and nanofiltration processes were assessed for different $\mathrm{ZnO}$ and $\mathrm{MB}$ dye concentrations. To the best of our awareness, no such research is investigated so far in the literature for the decolorization and degradation of the MB dye from aqueous media.

\section{Materials and Method}

\subsection{Materials}

Methylene Blue dye $\left(\mathrm{C}_{16} \mathrm{H}_{18} \mathrm{ClN}_{3} \mathrm{~S}\right)$ and $\mathrm{Zinc}$ oxide $(\mathrm{ZnO})$ photocatalyst were procured from M/s Sisco Research Laboratories Pvt. Ltd. Maharashtra, India. Sulfuric acid (98\%) and NaOH pellets were purchased from M/s SD Fine Chemicals Ltd., Mumbai, India. All the chemicals used in this research work are analytical grade. Except for $\mathrm{NaOH}$ and $\mathrm{H}_{2} \mathrm{SO}_{4}$ all other chemicals were utilized as collected from the provisioner.

\subsection{Experimental set-up and Methodology}

The schematics of the integrated system exercised in this work for decolorization and degradation of MB dye from aqueous media is shown in Fig. 1. A feed tank of $10 \mathrm{~L}$ volume was mounted with a $250 \mathrm{~W}$ UV light from the top. 


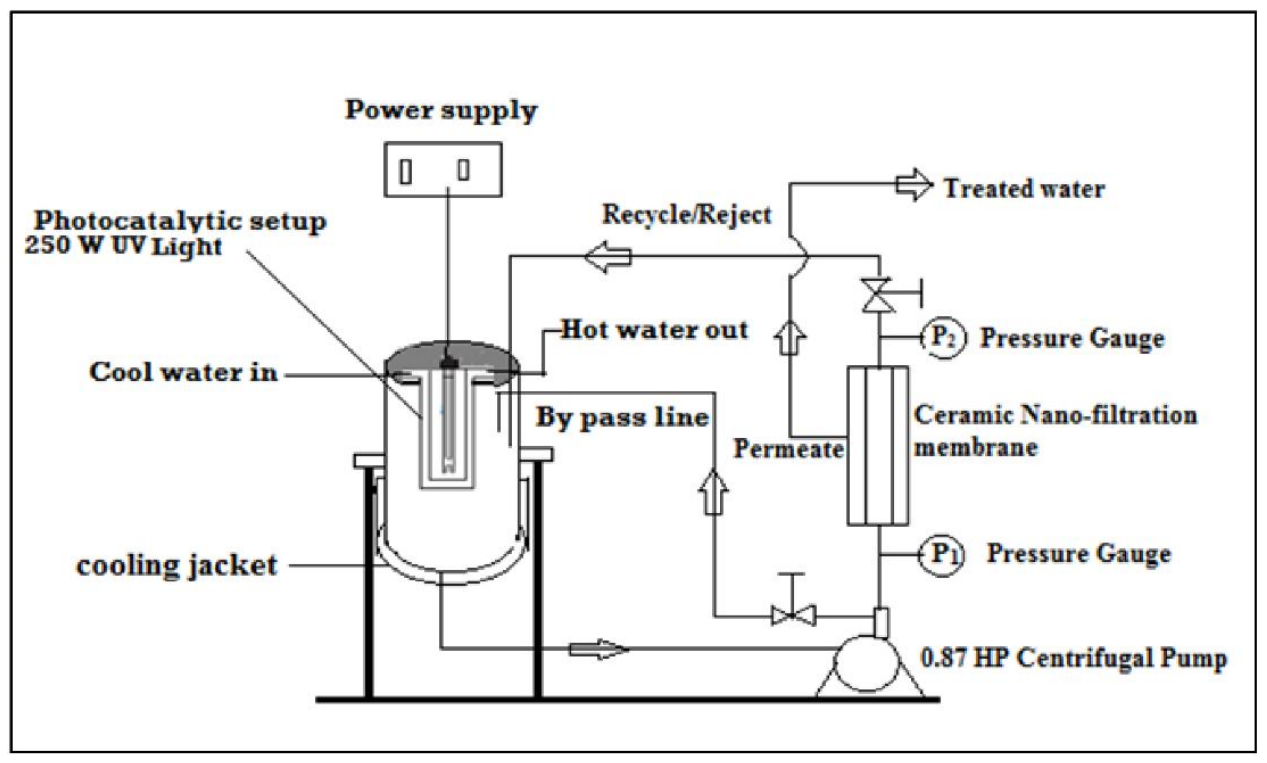

Fig.1 Experimental setup of the hybrid system

The stainless steel (SS-316) was used for the construction of photocatalytic reactor, and it was provided with a cooling jacket to keep the temperature constant inside the reactor. Centrifugal pumps of $0.87 \mathrm{HP}$ were connected at the rear side of the setup to pump wastewater through the nanofiltration unit. The commercial tubular ceramic membrane module procured from M/s TAMI Industries was used for the typical experiments. The tubular ceramic membrane consists of single or multi-channels with a titanium oxide active layer on the tube side surface.

Table 1: Technical Parameters

\begin{tabular}{|c|c|}
\hline Parameter & Semi pilot installation \\
\hline Configuration & Tubular \\
\hline Membrane material & Titanium oxide \\
\hline Effective surface area $\left(\mathrm{m}^{2}\right)$ & 0.3 \\
\hline Number of Channels & 3 \\
\hline Internal channel diameter $(\mathrm{mm})$ & 3.5 \\
\hline External membrane diameter $(\mathrm{mm})$ & 10 \\
\hline Membrane length $(\mathrm{mm})$ & 600 \\
\hline
\end{tabular}

The typical specifications of the commercial ceramic membrane module used in this study are given in Table 1. Control valves, Rota meter and Pressure gauges were arranged at desired locations between the reactor and nanofiltration unit to adjust and support the required flow rates and pressures. For the higher efficiency and enhancement in the degradation and 
decolorization of dye, the retentate from the nanofiltration unit was reprocessed to the feed tank. The permeate was fetched in test tubes at every 15 minutes of time interval.

In the course of filtration, the permeate and retentate samples were regularly collected for every $15 \mathrm{~min}$ and analyzed for dye concentration in both permeate and Retentate. The permeate volume flux $(\mathrm{J})$ is determined using the following equation (1):

$$
\mathrm{J}=\frac{V}{t \cdot A} \mathrm{~m}^{3} / \mathrm{m}^{2} \text { day }
$$

Where,

$\mathrm{V}=$ Permeate volume $\left(\mathrm{m}^{3}\right)$

$\mathrm{t}=$ time (day)

$\mathrm{A}=$ effective membrane area $\left(\mathrm{m}^{2}\right)$

The percentage rejection of dye by nanofiltration unit was determined using equation (2).

$$
\text { Dye rejection }(\%)=\frac{C_{r}-C_{p}}{C_{r}} * 100
$$

Where,

$\mathrm{C}_{\mathrm{r}}=$ concentration of dye $\left(\mathrm{g} / \mathrm{m}^{3}\right)$ in retentate

$\mathrm{C}_{\mathrm{p}}=$ concentration of dye $\left(\mathrm{g} / \mathrm{m}^{3}\right)$ in permeate

\subsection{Optimization of process parameters}

RSM is a convenient experimental design method which benefits in systematic resource utilization. RSM has enormous advantages, and this design technique can be used to develop, improve and optimize experimental parameters. RSM design models used in the evaluation of integrated system of Photocatalysis with nanofiltration resulted in fewer resources utilization and better outputs.

Table 2: CCD matrix with low and high values

\begin{tabular}{|c|c|c|}
\hline Factor & Range & Response (R1) \\
\hline Catalyst loading (A) & $0.1 \mathrm{~g} / \mathrm{L}-0.3 \mathrm{~g} / \mathrm{L}$ & \multirow{2}{*}{ \% MB Dye Decolourization } \\
\cline { 1 - 2 } $\mathrm{pH}(\mathrm{B})$ & $3-7$ & \\
\hline Time (C) & $80-100$ & \\
\hline
\end{tabular}

In this study, the central composite design (CCD) technique of RSM has been adapted for the optimization of operating parameters of photocatalysis combined with nanofiltration. Several experiments were conducted in different combinations that are generated by CCD matrix. The 
operating parameters optimized are; Catalyst loading - A (g/L), $\mathrm{pH}-\mathrm{B}$ and Time - C (Min) [28][29]. The initial factors, their ranges and the response are mentioned in Table 2.

\subsection{Characterization and Analysis}

The commercial ZnO powder was characterized using X-Ray Diffraction (XPERT-PRO) and particle size distribution analyzer (Malvern zeta sizer Instrument) to confirm the crystalline nature and particle size of photocatalyst. For identifying the decolorization of MB dye in aqueous media, UV-Vis Spectrophotometer (Evolution 300 supplied by Thermo scientific, UK) was utilized. The maximum absorbance $(\lambda \max )$ of $\mathrm{MB}$ dye is $663 \mathrm{~nm}$. The standard calibration chart was prepared and used for the identification of concentration of permeate collected at different time intervals. TOC analyzer (TOC LCPN analyzer, Shimadzu, Japan) was employed to determine mineralization of organic carbon in aqueous media.

\section{Results and discussion}

\subsection{Inlet operating pressure and its effect on permeate flux}

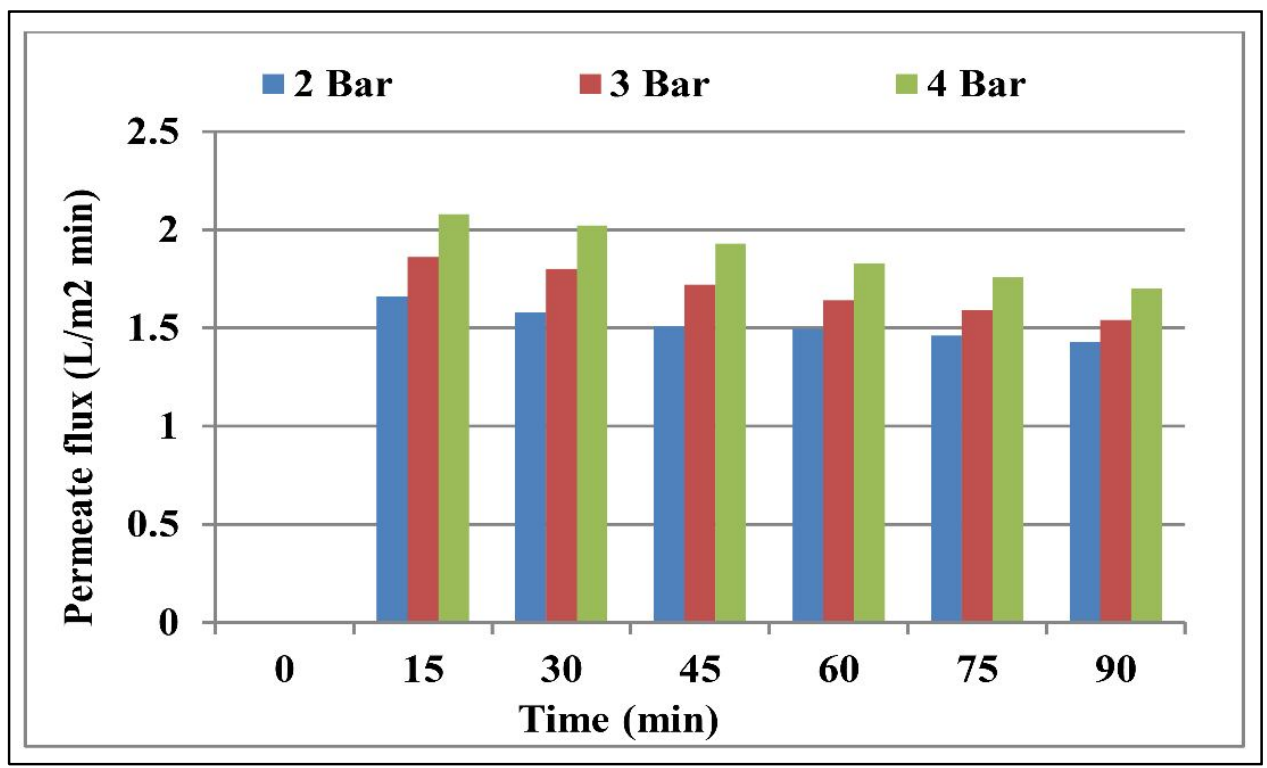

Fig.2 Inlet pressure and its effect on permeate flux in the hybrid system

Due to the diffusion model, the flux through the membrane is likely to increase with an increase in inlet pressure. An appropriate driving force is necessary to overcome the membrane surface fouling and membrane resistance. With the increase in feed pressure, the appropriate driving force can be obtained. The impact of inlet pressure on nanofiltration for the dye eviction demonstrates proportional relationship to flux and pressure. The impact of distinct inlet pressures to the nanofiltration for dye removal is shown in Fig.2. 
From the results, it was observed that the permeate flux of membrane increases with respect to the increase in the inlet pressure from 2 to 4 bars. However, with the progress of operation, the flux through the nanofiltration was reduced from 1.66 to $1.43,1.86$ to 1.54 , and 2.08 to $1.7 \mathrm{l} / \mathrm{m}^{2} . \min$ at 2,3 , and 4 bars respectively over $90 \mathrm{~min}$ of operation. The reduction in flux across the membrane could be due to concentration polarization or fouling of organic pollutants on the membrane surface. From the obtained results, it was identified that 4 bar inlet pressure had shown higher permeate flux across the membrane among different inlet pressures.

The polarization of organic contaminats on the membrane surface might be the reason for the decline of flux. In this study, at 4 bar greater flux values were observed [30-38].

\subsection{Catalyst loading and its effect on dye decolorization and degradation}

The effect of catalyst loading on the dismissal of MB dye was studied by varying the dosage of $\mathrm{ZnO}$ catalyst in the photocatalytic reactor. In the typical experiments, the photocatalytic reactor was charged with $5 \mathrm{~L}$ of $\mathrm{MB}$ dye wastewater containing $500 \mathrm{mg} / \mathrm{L}$ of concentration. Dye removal studies were carried out using hybrid system at 4 bar inlet pressure and various catalyst dosages such as $0.1,0.2,0.5$ and $1.0 \mathrm{~g} / \mathrm{L}$.

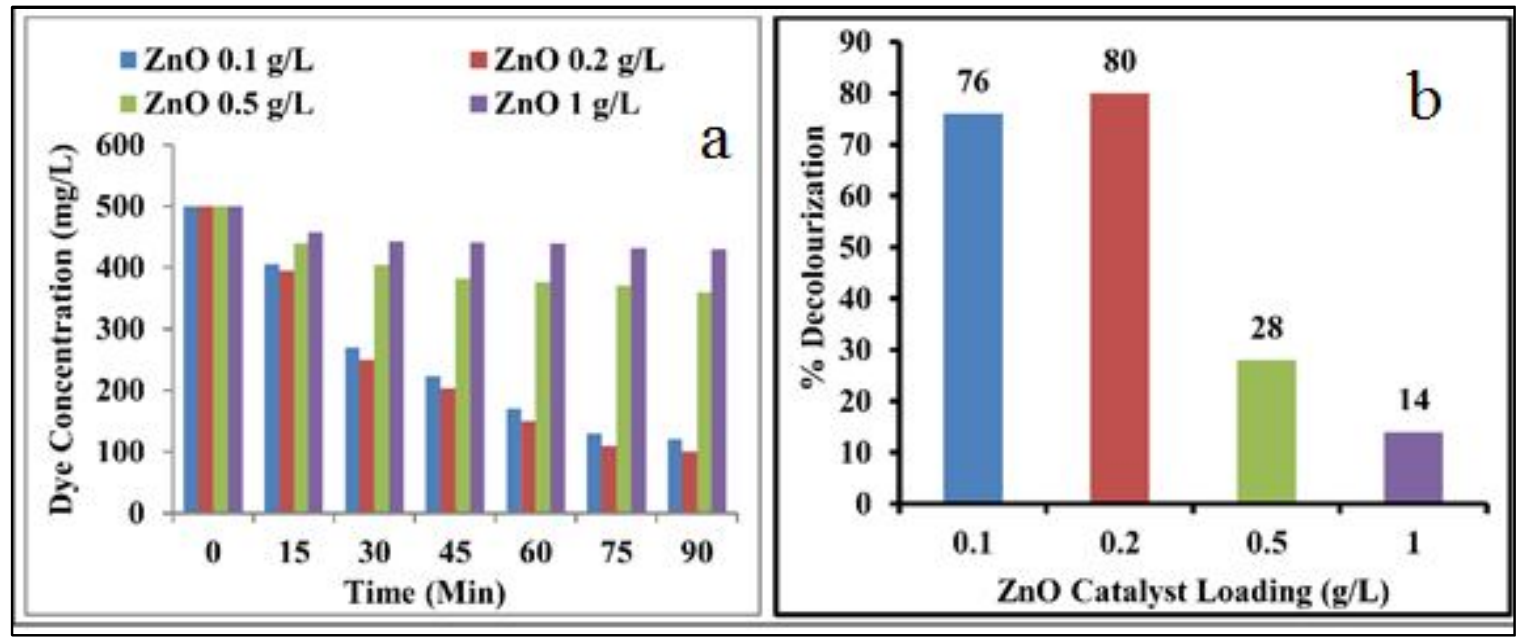

Fig.3(a). Effect of catalyst loading on dye removal in hybrid system [Initial concentration $=500 \mathrm{mg} / \mathrm{L}, 4$ bar inlet pressure]. 3(b). Percentage decolorization of MB dye in hybrid system at different catalyst loadings [Initial concentration=500 mg/L, 4 bar inlet pressure]

The operating temperature of the hybrid system was kept constant at $25{ }^{\circ} \mathrm{C}$. From the results, it was identified that the $0.2 \mathrm{~g} / \mathrm{L}$ of $\mathrm{ZnO}$ catalyst posses the maximum photocatalytic activity towards mineralization and decolorization of $\mathrm{MB}$ dye in aqueous media. Around $80 \%$ of 
decolorization of MB dye was achieved by integrating the process of photocatalysis with nanofiltration. The effect of dosage of $\mathrm{ZnO}$ catalyst for decolorization and the percentage reduction of MB dye is shown in Fig.3a and Fig.3b, respectively.

From the achieved results, it was observed that $0.1,0.2,0.5$, and $1.0 \mathrm{~g} / \mathrm{L}$ of the catalyst dosage had resulted in $76,80,28$, and $14 \%$ of dye decolorization respectively in the combined system. Catalyst dosage beyond $0.2 \mathrm{~g} / \mathrm{L}$ has shown lower dye decolorization. This effect might be due to aggregation of catalyst particles at excess loading which shows that the adsorption of dye molecules decreases due to the depletion of total available active sites on the catalyst surface. Moreover, the higher loading of catalyst resulted in high turbidity of wastewater that minimizes the transmittance of light across wastewater during irradiation. This ultimately deactivates the active catalyst molecules by smashing with ground-state molecules [32]. This study concludes that $0.2 \mathrm{~g} / \mathrm{L} \mathrm{ZnO}$ dosage is sufficient to attain better decolorization of MB dye using hybrid system. Therefore, $0.2 \mathrm{~g} / \mathrm{L}$ of $\mathrm{ZnO}$ catalyst was observed as optimal catalyst dosage for MB dye removal and further studies were carried out at this optimized catalyst dosage.

Pair of holes and electrons will be generated in the valence and conduction band when the electrons present in the $\mathrm{ZnO}$ valence band exhilarates upon irradiation of $\mathrm{ZnO}$ surface by the UV light. A positive hole $\left(\mathrm{h}^{+}\right)$and negative electron $\left(\mathrm{e}^{-}\right)$pair were generated because of the elevation of electron to the $\mathrm{ZnO}$ conduction band by the surplus energy of the exhilarated electron. The neighbouring water molecules get absorbed by the $\mathrm{h}^{+}$and split them to form the $\mathrm{H}_{2}$ radicals and gas. A superoxide anion $\left(\mathrm{O}_{2}{ }^{-}\right)$will be formed when the $\mathrm{O}_{2}$ molecules react with the $\mathrm{e}^{-}$and $\mathrm{h}^{+}$of $\mathrm{ZnO}$. Sequence of reactions are commenced on the $\mathrm{ZnO}$ surface because of the periodic production of hydroxyl radicals [39]. The adsorbed $\mathrm{H}_{2} \mathrm{O}$ and $\mathrm{OH}$ reacts with the holes to form the hydroxyl radicals.

$$
\left[\text { Dye-Na] } \rightarrow\left[\text { dye }^{-}\right]+\mathrm{Na}^{-}\right.
$$

The $\mathrm{OH}$ radicals production will be lowered if the dye ions substitute the adsorbed $\mathrm{OH}$ radicals. The catalyst required for the degradation increases with the increase in initial dye concentration. In this study, on increasing the concentration of the dye, the $\mathrm{O}_{2}{ }^{-}$and $\mathrm{OH}$ radicals were decreased because of the constant quantity of the catalyst and the illumination time. This proves the decrease in efficiency of the photocatalytic degradation [39].

\subsection{Effect of initial pH}

Different initial $\mathrm{pH}$ ranging from $\mathrm{pH} 1.0$ to $\mathrm{pH} 10.0$ was studied for decolorization of $\mathrm{MB}$ dye and removal of TOC using hybrid system. The $\mathrm{pH}$ of wastewater was adjusted by using 
diluted $\mathrm{NaOH}$ and $\mathrm{H}_{2} \mathrm{SO}_{4}$. The primary dye concentration and $\mathrm{ZnO}$ catalyst dosage were fixed as $500 \mathrm{mg} / \mathrm{L}$ and $0.2 \mathrm{~g} / \mathrm{L}$ discretely for all the $\mathrm{pH}$ experiments.

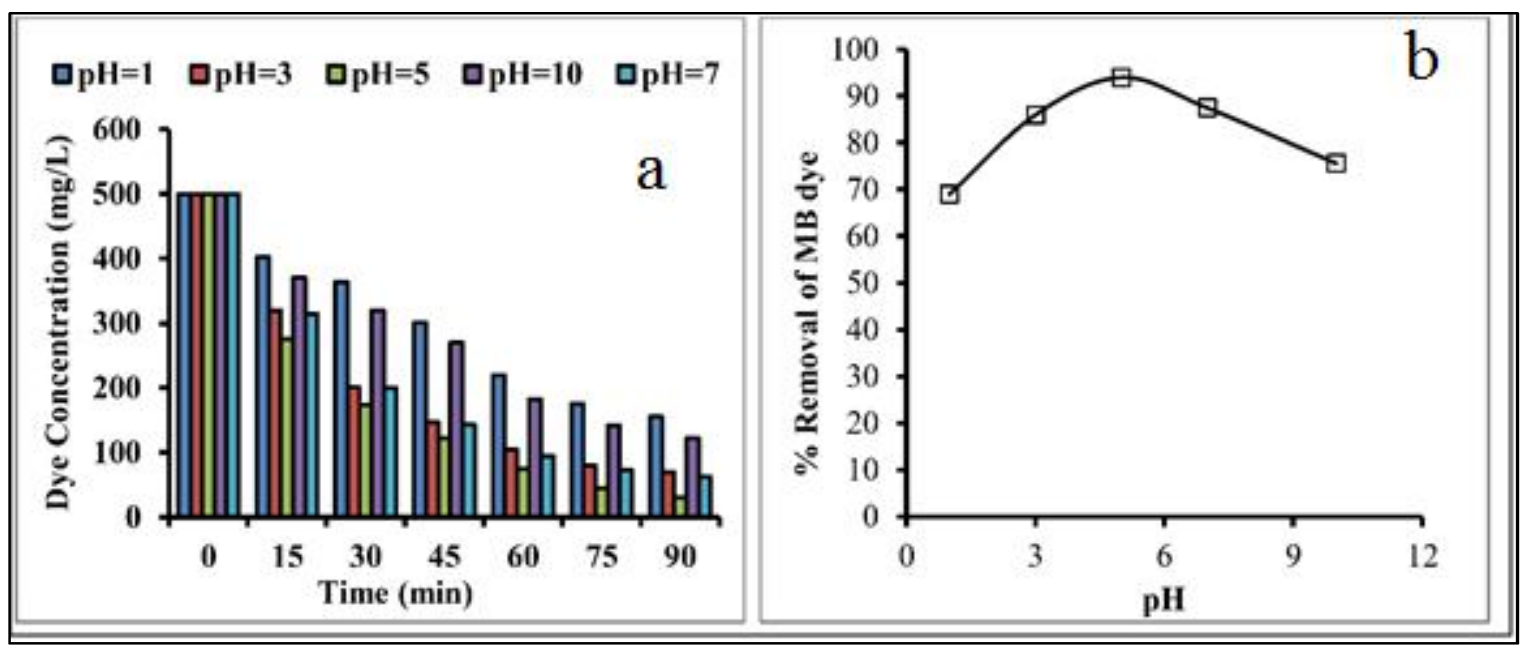

Fig.4(a). Effect of initial pH of dye solution on the removal of MB dye in hybrid system

[Initial concentration $=500 \mathrm{mg} / \mathrm{L}$, Catalyst loading $=0.2 \mathrm{~g} / \mathrm{L}] .4(\mathrm{~b})$. Percentage decolorization of MB dye in hybrid system at various $\mathrm{pH}$ values [Initial concentration $=500 \mathrm{mg} / \mathrm{L}$, Catalyst loading $=0.2 \mathrm{~g} / \mathrm{L}]$

Fig. 4a depicts the effect of different solution $\mathrm{pH}$ on dye decolorization in the integrated process. It was observed that decolorization of MB dye was achieved up to $69,85.98,94$, 87.5, and $75.6 \%$ at $\mathrm{pH} 1,3,5,7$, and 10 respectively in the combined process of photocatalysis and nanofiltration. From Fig.4b, it was noticed that with an escalation in $\mathrm{pH}$ to 5 , the decolorization of dye had been increased gradually, whereas decolorization and mineralization rate of organic carbon has been decreased after $\mathrm{pH} 5$. From the obtained results, it has been found that $\mathrm{pH} 5.0$ is an optimum value to achieve desired results. This could be due to adsorption of MB dye on the catalyst surface which is reliant on its surface charge. At $\mathrm{pH} 5$, the $\mathrm{ZnO}$ surface might be negatively charged due to generation of massive hydroxyl radicals, which simplifies the adsorption of $\mathrm{MB}$ dye and also its self-sensitized breakdown [33].

Moreover, the solution $\mathrm{pH}>5$ could have imparted negative charge to $\mathrm{ZnO}$ surface, consequently inhibiting dye degradation by lower adsorption of dye molecules onto $\mathrm{ZnO}$ surface. It was reported that production of hydroxyl radical was favored at high $\mathrm{pH}$ [25]. However, the hydroxyl ions can also be generated by lurking the photogenerated holes on the surface of $\mathrm{ZnO}$ particles. These hydroxyl ions compete with direct oxidative breakdown of dye by holes in the valence band of $\mathrm{ZnO}$. 
$\mathrm{ZnO}$ liquefies in basic as well as acidic medium because of its amphoteric nature. Mosaic like structres namely $\left[\mathrm{Zn}(\mathrm{OH})_{4}\right]^{2-}$ are formed by $\mathrm{ZnO}$ in alkaline $\mathrm{pH}$ and corresponding salts in acidic $\mathrm{pH}$. Because of the photo dissolution and dissolution, $\mathrm{ZnO}$ exhibits less reactivity. The hydroxyl radical production is also considered as the $\mathrm{pH}$ function [35-38]. The development of hydroxial radicals, dye molecule detachment and $\mathrm{ZnO}$ surface properties are affected by the $\mathrm{pH}$ [40]. Akyol et al. [41] has reported the ZnO's zero point charge (zpc) as $6 \pm 0.3$. Because of the adsorbed $\mathrm{OH}^{-}$ions, the $\mathrm{ZnO}$ surface is negatively charged above $\mathrm{pH} 6$ and below this, it is positively charged. The $\mathrm{OH} \bullet$ radicals development is more supportive when huge amounts of $\mathrm{OH}^{-}$ions are present in the reaction medium as well as on the surface of the particle. Under $\mathrm{pH}$ 6, the decolourization as well as the process efficiency increases.

Baslak et al. [42] by employing quantum dots (QDs) cellulose membrane and CdTeSe investigated the Rhodamine-B (RB) transportation mechanism. At high $\mathrm{pH}$, the QDs and CdTeSe were expedited to transfer the RB in to stripping phase. The study has revealed that the feed phase $\mathrm{pH}$ should be more than the $\mathrm{pH}$ of the stripping phase and $\mathrm{pH} 12$ is regarded as the optimum $\mathrm{pH}$ for the utmost $\mathrm{RB}$ transportation. RB-QDs complex were developed, $\mathrm{RB}$ subsisted as ionic form and CdTeSe QDs were deprotonated at these conditions. The dissimilarities between the $\mathrm{pH}$ of feeding and stripping phases is the reason for the driving force of diffusion of RB ions.

\subsection{Effect of initial Dye concentration}

The decolorization of MB dye in the hybrid system was investigated by altering initial dye concentration between 250 and $1000 \mathrm{mg} / \mathrm{L}$, and the catalyst loading was kept constant as 0.2 $\mathrm{g} / \mathrm{L}$. The samples collected at regular time intervals from the permeate were tested under UV absorbance to calculate the percentage decolorization. From the results, it was identified that rise in dye concentration led to minimal decolorization. Fig.5a and $5 \mathrm{~b}$ depict the effect of primary concentration of MB dye on the performance of hybrid system. The decrease in the dye decolorization at higher initial concentrations is due to lower reactivity of hydroxyl radicals. The other rationale might be enhancing the filter impact of dye in the blend [24]. It was perceived that the efficiency of the process was increased at higher initial concentrations with regard to complete amount of dye eviction. The initial dye concentrations used in this work are 250, 500, 750, and $1000 \mathrm{mg} / \mathrm{L}$ and these concentrations have shown decolorization about $95.68,93.12,88$, and $83.96 \%$, respectively. 


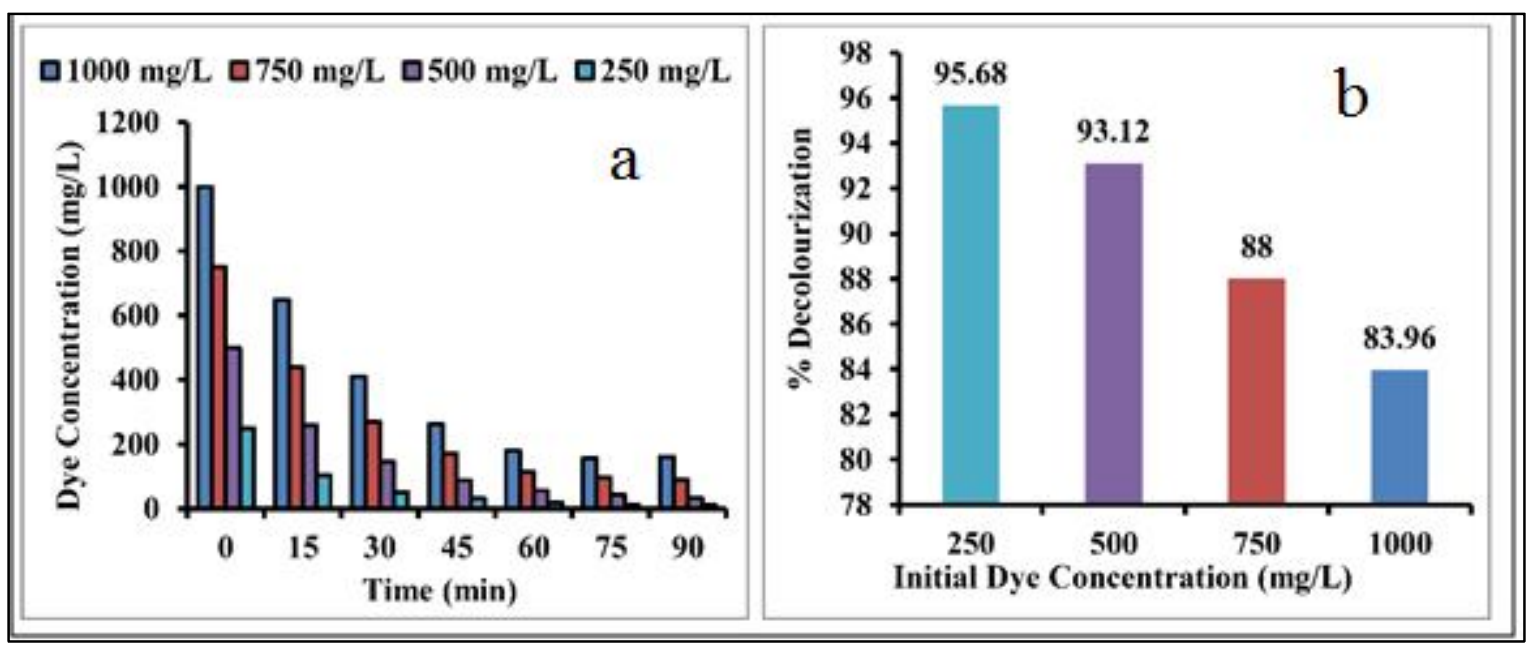

Fig.5(a). The Effect of initial dye concentration in the hybrid system [Catalyst loading $=0.2 \mathrm{~g} / \mathrm{L}$, $\mathrm{pH}=5$ ]. 5(b). Effect of initial dye concentration on percentage decolorization of MB dye in hybrid system [Initial concentration $=500 \mathrm{mg} / \mathrm{L}$, catalyst loading $=0.2 \mathrm{~g} / \mathrm{L}$ ]

From the experimental outcomes it was noticed that the decolourization of dye declined with the escalation of dye concentration. The constant illumination time and light intensity, and catalyst surface are the rationale for this decline. Based on the surface given by the catalyst, the dye has been adsorbed on its surface. The $\mathrm{O}_{2}{ }^{-}$and $\mathrm{OH}$ which were developed on the photocatalyst surface were also persistent. Due to this reason, when the dye concentration enhances, the strength of the $\mathrm{O}_{2}{ }^{-}$and $\mathrm{OH}$ declines, which eventually leads to decrease in photo-degradation efficiency. As the active sites are protected by the dye ions, at high dye concentrations the $\mathrm{OH}^{-}$radicals generation on the catalyst surface is reduced [32-38].

\section{Model Development, Regression analysis and optimization through RSM}

In the past few decades, many researchers have focused their efforts in the field of optimization of wastewater treatment technologies using various models. However, RSM methodology was shown to be an effective optimization model for the operating parameters. Wang et al. [43] applied the response surface process (RSM) to optimise the initial parameters such as $\mathrm{pH}$, flocculent and coagulant dosage for the treatment of paper recycling wastewater. The confirmation experiments have revealed the RSM as the best suitable method for the optimization of initial parameters of coagulation-flocculation process. Moghaddam et al. [44] examined the functioning of $\mathrm{FeCl}_{3}$ sludge for the acid red 119 (AR119) dye removal. The three operating variables such as initial dye concentration, coagulant dosage and initial $\mathrm{pH}$ of coagulation/flocculation process were optimised by using response surface methodology (RSM). $96.53 \%$ of dye removal was observed in this experimental study, and this was very close to the RSM results. This study has concluded 
that, for the optimization of operating variables of coagulation/flocculation process, the RSM is considered as a cogent tool. Salahi A et al. [45] worked on the oily wastewater treatment in a desalter plant by using a $10 \mathrm{~nm}$ nominal pore size nano-porous membrane (PAN) sheet. The initial operating variables such as $\mathrm{pH}$, cross-flow velocity (CFV), salt concentration, feed temperature, and trans-membrane pressure (TMP) were optimized by employing response surface methodology (RSM). The experimental results are likewise to the RSM results. Hence it was mentioned that the RSM as an efficient method for the optimization process which reduces capital and saves time. Yuliwati E et al. [46] studied the impact of operating parameters on the treatment of refinery wastewater in submerged ultrafiltration. In this study, various parameters including $\mathrm{pH}$, mixed liquor suspended solids (MLSS) concentration, hydraulic retention time (HRT), air bubble flow rate (ABFR) were optimized by using response surface methodology (RSM). From the obtained results it was observed that the application of RSM had surpassed the removal of COD and water flux.

In this study, ANOVA for Response Surface Quadratic Model was used to design and analyse the operating parameters for the MB dye degradation using photocatalysis and nanofiltration.

Three factors CCD matrices were designed for this work. Final Equation in Terms of Coded Factors:

$\% \mathrm{MB}$ dye decolourization $=94.08-0.16 A+1.20 B+2.04 C+0.090 A B+0.81 A C+$ $0.55 B C-6.54 A^{2}-7.41 B^{2}-0.64 C^{2}$

From the results, it was noticed that the experimental and predicted values are in good agreement with each other. The mutuality between the predicted and the experimental data was quantitatively assessed by the $\mathrm{R}^{2}$ value. The generated equation (3) was used to compare the predicted and experimental data. From the mathematical model it was observed that the experimental results were effectively agreed with the correlation coefficient $\left(R^{2}=0.9898\right)$. From the model it is also observed that the adjusted $R^{2}\left(\operatorname{Adj}-R^{2}=0.9806\right)$ value was near to that of the $\mathrm{R}^{2}$ value and it is also in a good fit.

The ANOVA for Response surface quadratic model was performed and included in table 3. The Predicted responses were in good agreement with the experimental outcomes. In the ANOVA test, the model variance can be compared with the residual variance using the F-test. The lack of fit is known to be notable if Prob>F-value. F Value in this test is 107.61 with a parallel p-value of $<0.0001$ indicating $\mathrm{A}, \mathrm{B}$ and $\mathrm{C}$ are significant models. The $\mathrm{R}^{2}$ values in this test were preferable because of a good fit of the model [47]. 
Table 3: ANOVA for Response Surface Quadratic Model Analysis of variance table [Partial sum of squares - Type III]

\begin{tabular}{|c|c|c|c|c|c|}
\hline Source & Sum of Squares & df & Mean Square & F Value & p-value Prob > F \\
\hline Model & 898.64 & 9 & 99.85 & 107.61 & $<0.0001$ \\
\hline A-Catalyst Loading & 0.26 & 1 & 0.26 & 0.28 & 0.6086 \\
\hline B-pH & 14.47 & 1 & 14.47 & 15.60 & 0.0027 \\
\hline C-Time & 41.53 & 1 & 41.53 & 44.76 & $<0.0001$ \\
\hline $\mathbf{A B}$ & 0.065 & 1 & 0.65 & 0.070 & 0.7969 \\
\hline $\mathbf{A C}$ & 5.22 & 1 & 5.22 & 5.62 & 0.0392 \\
\hline BC & 2.44 & 1 & 2.44 & 2.63 & 0.1358 \\
\hline $\mathbf{A}^{\mathbf{2}}$ & 117.56 & 1 & 117.56 & 126.70 & $<0.0001$ \\
\hline $\mathbf{B}^{\mathbf{2}}$ & 150.92 & 1 & 150.92 & 162.66 & $<0.0001$ \\
\hline $\mathbf{C}^{\mathbf{2}}$ & 1.14 & 1 & 1.14 & 1.23 & 0.2941 \\
\hline Residual & 9.28 & 10 & 0.93 & & \\
\hline Lack of Fit & 7.32 & 5 & 1.46 & 3.73 & 0.0875 \\
\hline Pure Error & 1.96 & 5 & 0.39 & & \\
\hline Cor Total & 907.92 & 19 & & & \\
\hline
\end{tabular}

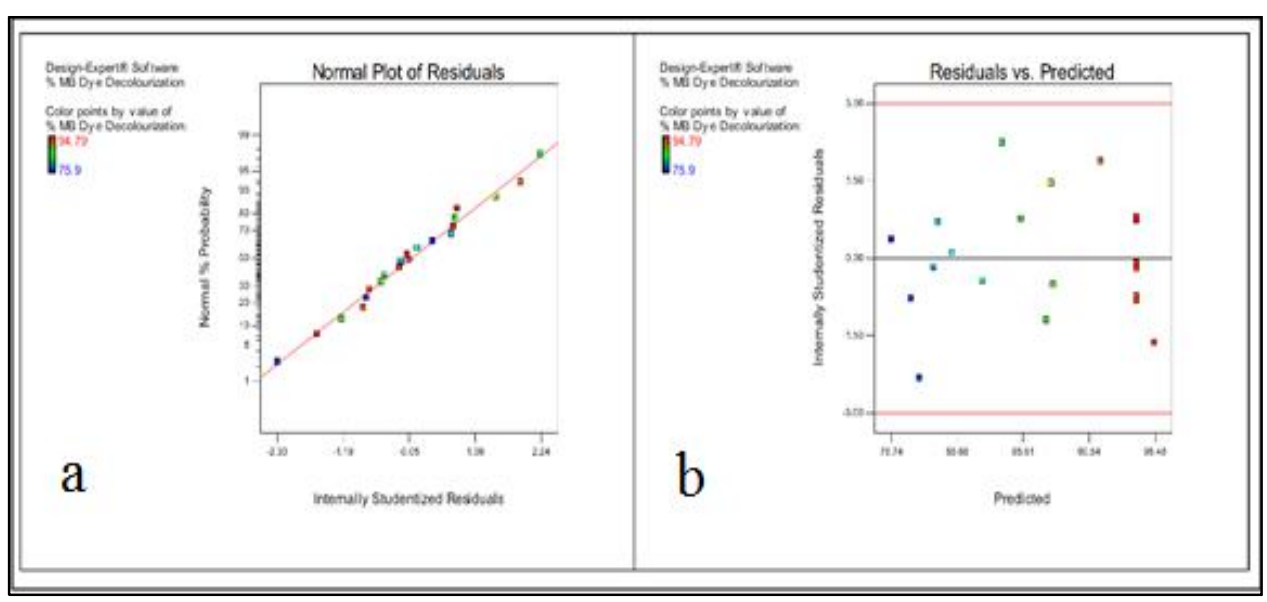

Fig. 6(a) Normal plot of Residuals, (b) Residuals vs Predicted

Besides $\mathrm{R}^{2}$, the effectiveness of the models was also analyzed using residuals. The normality of the residuals can be determined by using normal probability plots. The residuals present in the above Fig. (6a) were represented against the anticipated value. Feasible results can be observed in Fig.6b.

The purpose of this work is to generate the optimized input operating parameter values for the textile dye wastewater treatment using photocatalysis combined with the ceramic 
nanofiltration system. Experimental design models were employed to optimize the input operating factors. The desirable values of the process variables for the utmost decolorization ability were found to be $0.2 \mathrm{~g} / \mathrm{L}, 5.26,94.23$ for catalyst loading (A), $\mathrm{pH}(\mathrm{B})$ and Time (C) respectively. At these optimum values, the predicted and observed MB dye \% color removal was 94.8752 and $94 \%$, respectively.

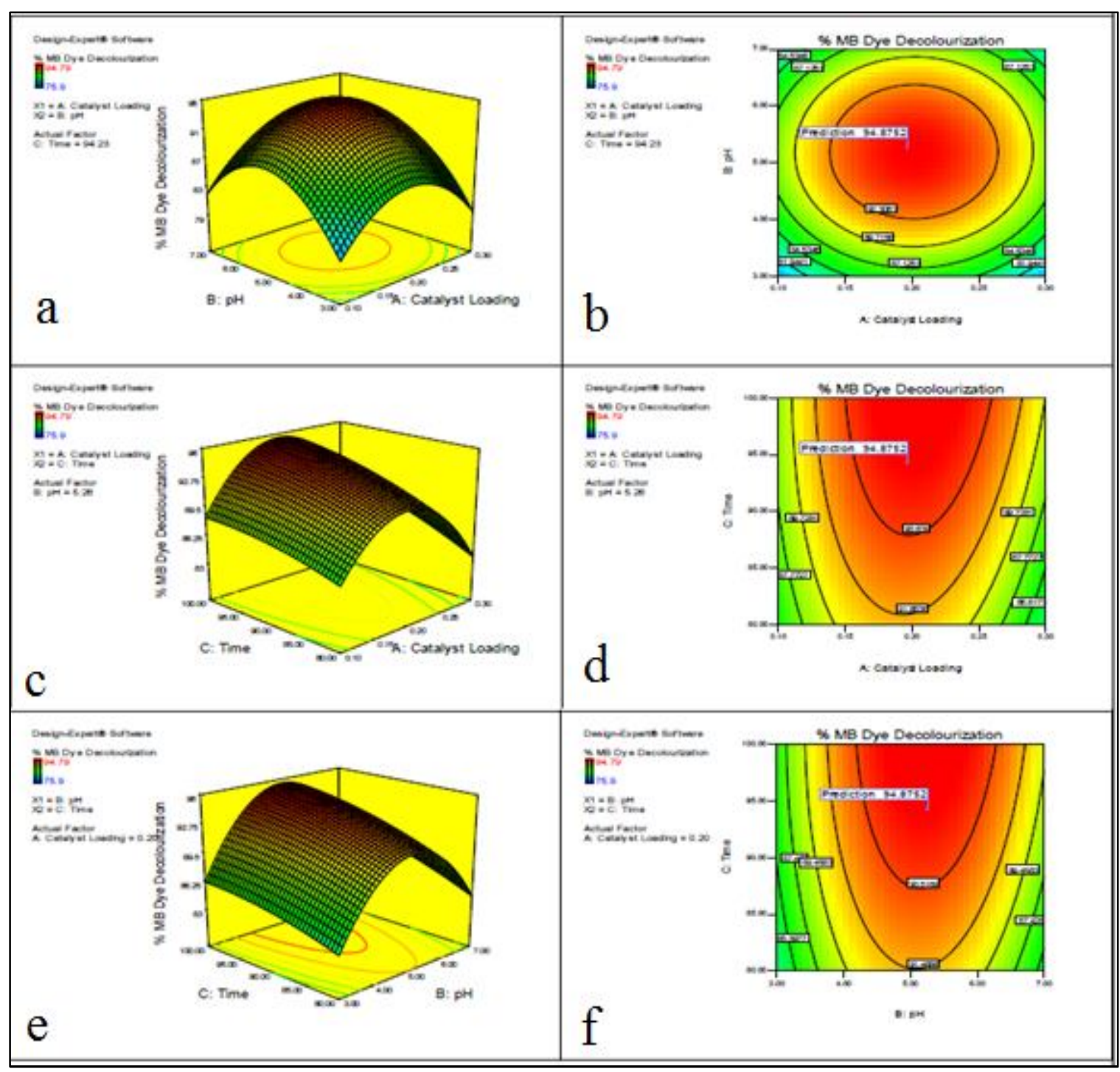

Fig. 7: Response surface plot showing mutual interactions between the input parameters to enhance \% CV decolorization. 7(a) pH Vs catalyst loading. 7(c) Time Vs catalyst loading. 7(e) Time Vs pH and 7(b)(d)(f) are contour plots 


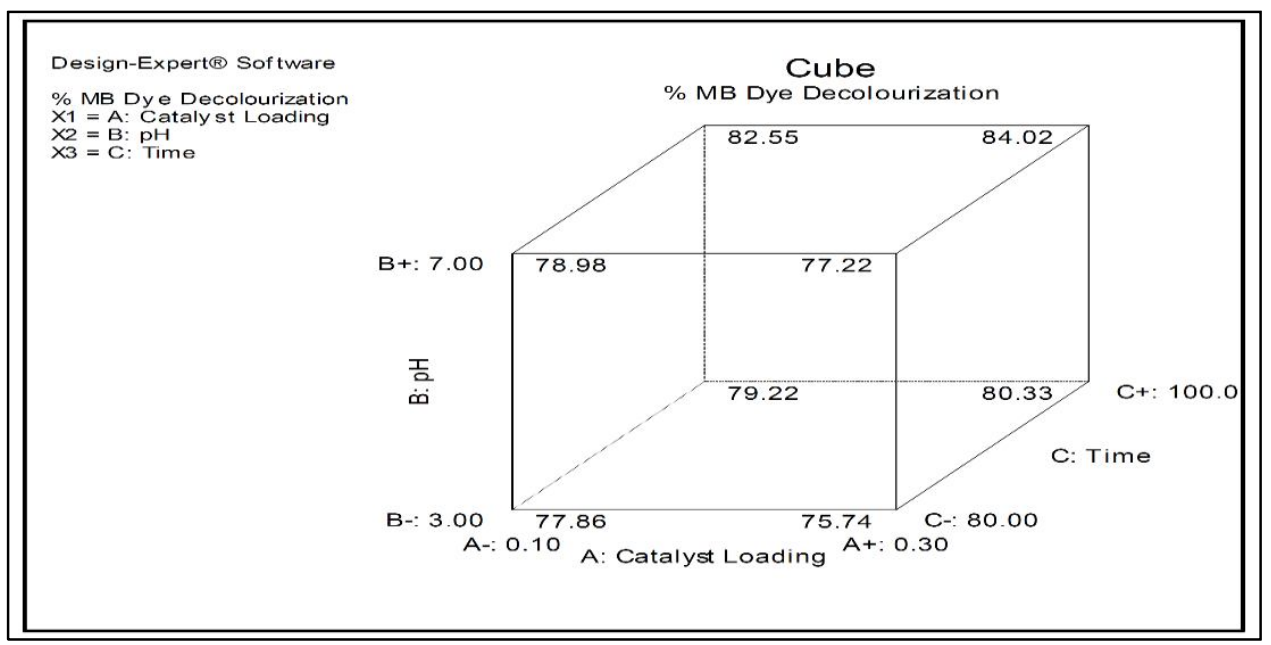

Fig 8: CCD Matrix

Figures 7 and 8 explain the response surfaces, contours and the CCD matrix developed for the optimization of operating parameters for dye decolorization using combined system.

The maximum decolorization was achieved when the experiments were conducted at the obtained optimum values. This can be concluded as the best approach for the effective MB dye decolorization using optimized operating parameters designed in the RSM experimental model. Hence this study is termed as successful.

\section{Comparison of individual and combined systems}

Individual operations were executed to explore the effect of various operating conditions on decolorization of $\mathrm{MB}$ dye. Initially, the equilibrium adsorption for $\mathrm{ZnO}$ catalyst was accessed before further experiments.

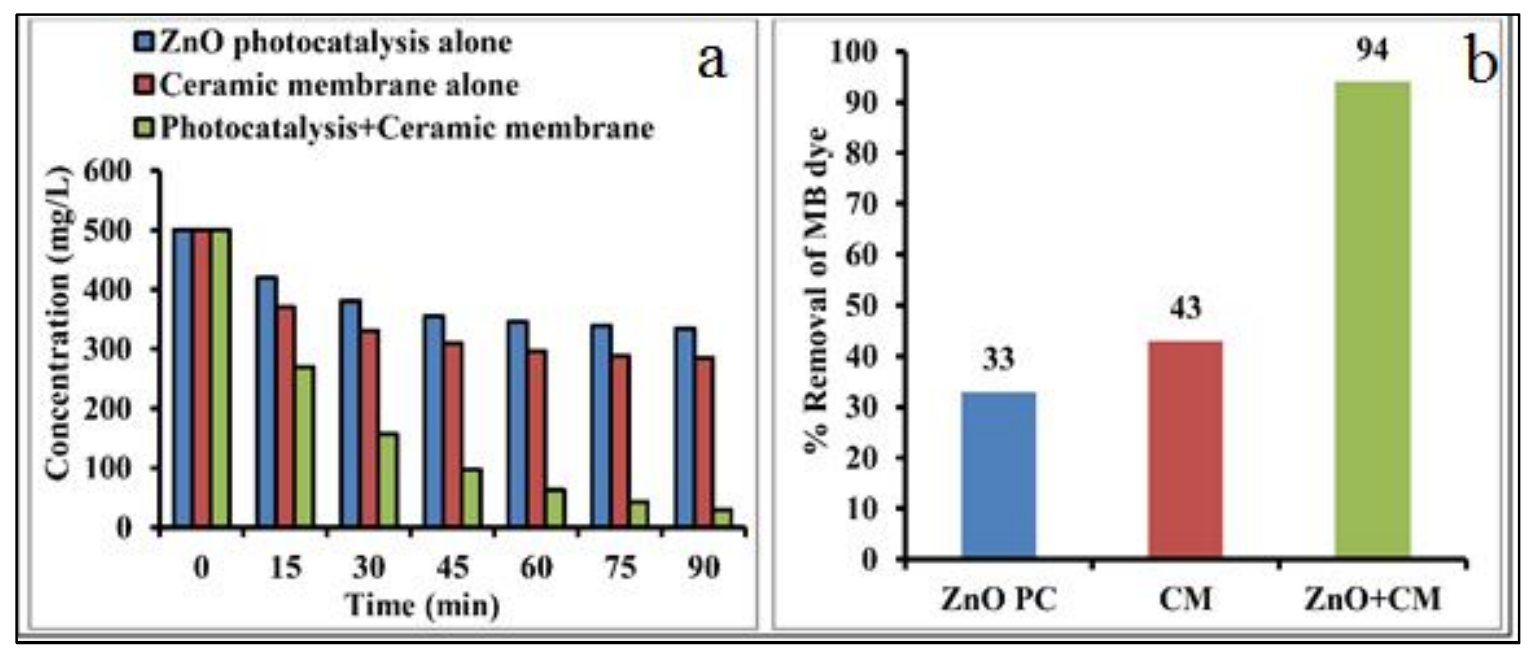

Fig.9 (a) Effect of initial concentration of dye in hybrid system [Catalyst loading $=0.2$ $\mathrm{g} / \mathrm{L}, \mathrm{pH}=5.26$, Time $94.23 \mathrm{~min}] .9(\mathrm{~b})$. Effect of the initial concentration of dye on Percentage decolorization of MB dye in hybrid system 
For this, initially, $0.2 \mathrm{~g} / \mathrm{L}$ of catalyst was supplemented to $1.0 \mathrm{~L}$ of $\mathrm{MB}$ dye solution. The solution was further blended using a magnetic stirrer in an unilluminated space to avoid passage of light. The above procedure was continued until the equilibrium adsorption was achieved. Within $60 \mathrm{~min}, 0.2 \mathrm{~g} / \mathrm{L}$ of $\mathrm{ZnO}$ reached the equilibrium state by adsorbing and degrading $90 \%$ of $\mathrm{MB}$ dye approximately. The effect of $\mathrm{ZnO}$ dosage on nanofiltration performance for the removal of dye was studied at optimized parameters such as $0.2 \mathrm{~g} / \mathrm{L}$ of $\mathrm{ZnO}$ and $\mathrm{pH}$ 5.26. Nanofiltration experiments were carried with $5 \mathrm{~L}$ of $500 \mathrm{mg} / \mathrm{L}$ of dye mixture. By using a centrifugal pump of $0.87 \mathrm{HP}$, the feed was pumped into the ceramic nanofiltration membrane at the desired pressure.

The pressure and the desired flow rate were adjusted using the manual control valve fixed in the main line. Alternatively, a circumvent line was provided to maintain the desired pressure at the inlet of the membrane. The influence of inlet pressure on the nanofiltration alone was also studied for the removal of $\mathrm{MB}$ dye at inlet pressures ranged from 2 to 4 bars. The performance of integrated nanofiltration and photocatalysis on dye reclamation was carried out with optimized operating factors; $0.2 \mathrm{~g} / \mathrm{L}$ of $\mathrm{ZnO}$ dosage and $\mathrm{pH}$ 5.26. It was perceived that the integration of photocatalysis with nanofiltration process shows $94 \%$ decolorization of MB dye. It was also noted that the hybrid system had shown the synergistic effect by the integration of photocatalysis with nanofiltration, as compared to individual operations. Fig.9a and $9 \mathrm{~b}$ illustrate the effect of individual and combined systems on removal of MB dye. Moradi et al. [48] were attempted with commercial nanofiltration membrane to treat the textile wastewater for reuse. In this work, the central composite face-centred technique of RSM methodology was used to design and optimize experimental conditions including $\mathrm{pH}$ (3-9), pressure (3-6 bar), and dye concentration (10-50 mg/l). From this study, it was concluded that large amount of dye rejection and clear water was attained in the permeate flux under acidic and alkaline conditions. The authors have concluded that the RSM design was efficient approach for optimizing the experimental conditions and attaining the desired outcomes. Askari et al. [49] worked on treatment of textile wastewater by employing thinfilm composite Nanofiltration (NF) membrane. Box-Behnken design of RSM method was employed to analyse the optimum operating conditions of the experiment including pressure, $\mathrm{pH}$ and dye concentration. At primary dye concentration of $180 \mathrm{mg} / \mathrm{L}$ and $\mathrm{pH} 10$ showed $92 \%$ of acid blue 25 and $91 \%$ of disperse red 73 were removed. At primary dye concentration of $40 \mathrm{mg} / \mathrm{L}$ and $\mathrm{pH} 3,86 \%$ of $\mathrm{MB}$ dye was removed. 
In addition to MB dye decolorization, Total organic carbon (TOC) was also analyzed and observed that $70 \%$ of TOC was removed at optimum loading parameters. Fig.10 shows the percentage removal of TOC in various systems.

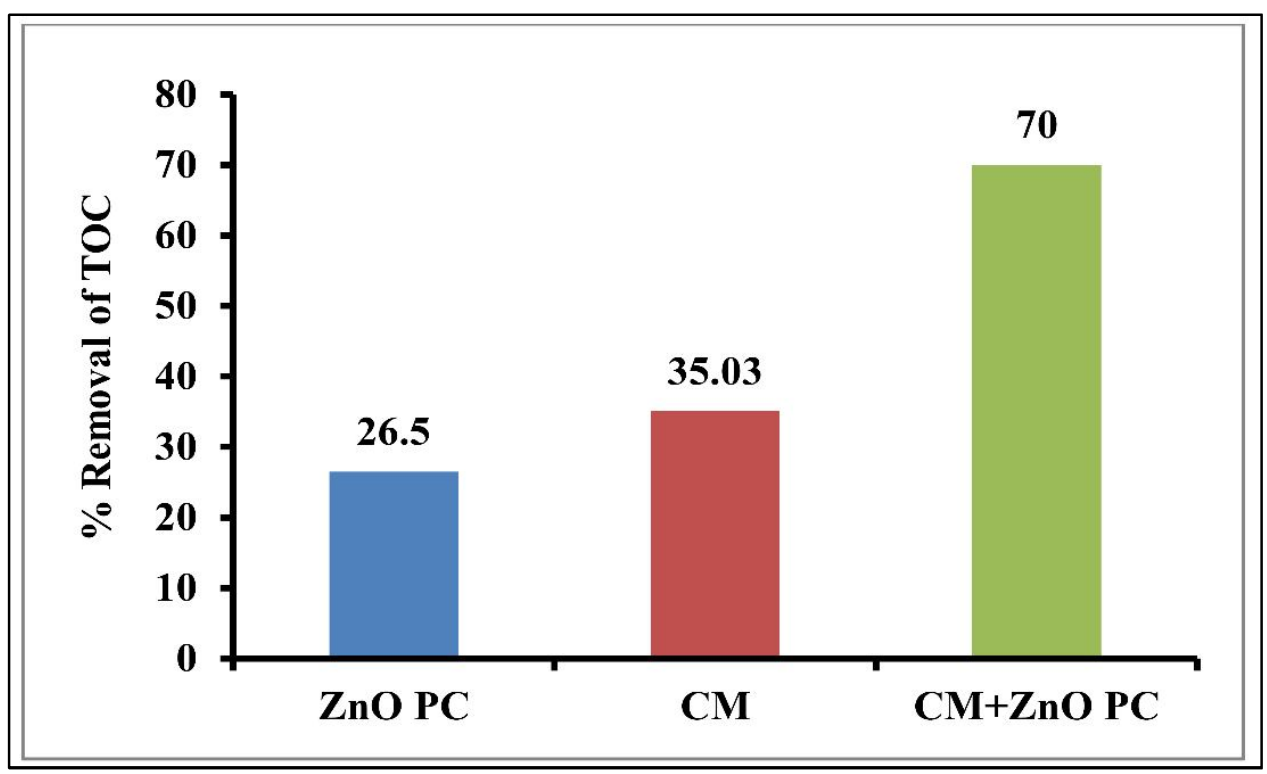

Fig.10. Percentage removal TOC of MB dye in various systems [Initial concentration $=500 \mathrm{mg} / \mathrm{L}$, Catalyst loading $=0.2 \mathrm{~g} / \mathrm{L}, \mathrm{pH}=5.26$, Time $94.23 \mathrm{~min}]$

Mortazavian et al. [50] worked on the breakdown of Acid Red 88 (AR 88) and Acid Blue 113 (AB 113) textile wastewater by employing $\mathrm{TiO}_{2}$ based photocatalytic process. In this study, the experiments were designed and optimized by using Response surface methodology (RSM). The importance of experimental parameters like initial dye concentration and $\mathrm{pH}$ medium were determined by employing the analysis of variance (ANOVA). From the obtained experimental outcomes, it was perceived that dye concentration and its $\mathrm{pH}$ had drastic effect on AR 88 (99.6\%) and AB 113 (98.7\%) degradation. Abdullah et al. [51] studied the Methylene blue (MB) dye degradation by employing Visible-light active (BiVO4) photocatalyst. In this study, authors have studied and optimized distinct operating parameters such as $\mathrm{pH}$, concentration of dye and mass loading. Response surface modelling was employed as an experimental design and optimization methodology for the MB dye removal. The quadratic model which was developed using this technique shows a functional relationship between the experimental parameters and $\mathrm{MB}$ dye removal. $67.21 \%$ of $\mathrm{MB}$ dye removal was observed from the optimized experimental results.

The efficiency of the individual systems collated with the integrated process was represented by the synergetic index. The TOC removal by the individual as well as the combined hybrid 
systems were explaned in detail in the fig. 10. The synergetic effect was assessed by using this data.

The synergetic index (SI) plays a crucial part in the investigation of photocatalysis during the membrane filtration process. This synergetic index (SI) is determined by the following equation:

$$
\begin{aligned}
\mathrm{SI}_{(\mathrm{PC}+\mathrm{CM})} & =\frac{[\% \mathrm{TOC} \text { removal }]_{(\mathrm{PC}+\mathrm{CM})}}{[\% \text { TOC removal }]_{(\mathrm{PC})}+[\% \text { TOCremoval }]_{(\mathrm{CM})}} \\
& =\frac{70}{26.5+35.03} \\
& =1.13
\end{aligned}
$$

The obtained result was more than 1 and it indicate the contaminant removal was higher in the integrated process than the removal observed in the individual systems together. The above obtained SI value expresses a notable synergy effect. Hence, it can be concluded that the combined hybrid technology is more efficient for the wastewater treatment than the individual systems.

\section{Kinetic studies of MB dye decolorization}

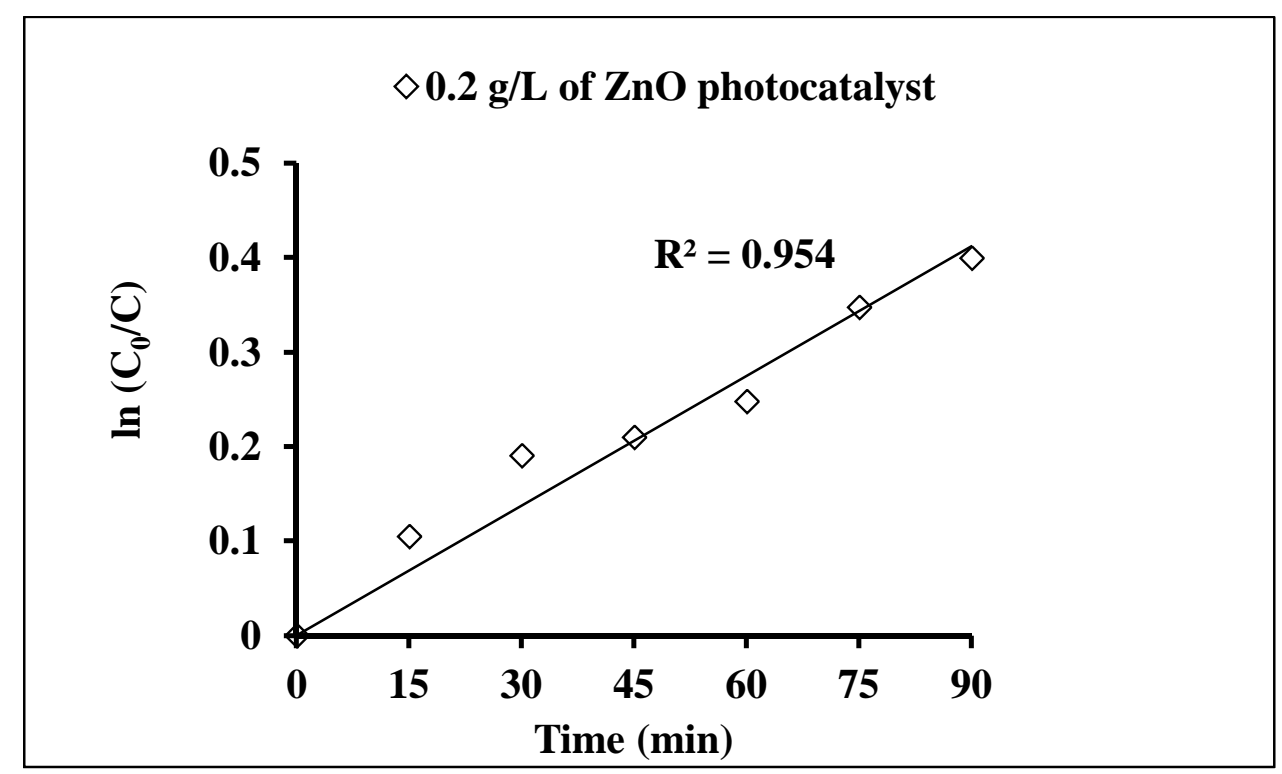

Fig 11. Pseudo-first-order decolorization of MB dye

During the Photocatalysis process, the $\mathrm{OH}$ radicals are generated, and these eventually degrade the organic pollutants present in the feed. These $\mathrm{OH}$ radicals are highly oxidative and readily react by attacking organic pollutants present in wastewater. Previous literature on photocatalysis for both decolorization and degradation of organic pollutants followed a 
pseudo-first-order reaction. The results achieved in this work also confirmed the same. The rate constant of the degradation reaction of dye is achieved by the following equation:

$$
\ln \frac{C_{0}}{C}=k t
$$

Where $\mathrm{C}=$ Concentration of dye solution, $\mathrm{mol} / \mathrm{L}, \mathrm{K}=$ rate constant, $\mathrm{min}^{-1}, \mathrm{t}=$ time, $\min$.

Fig.11 depicts the pseudo-first-order decolorization of MB dye in photocatalytic process. It was confirmed from the plot of $\ln \left(\mathrm{C}_{0} / \mathrm{C}\right)$ Vs time $(\mathrm{t})$ that a straight line is passing through the origin. From this plot, the decolorization rate constant (k) of MB dye was found to be 0.004 $\min ^{-1}$.

\section{Conclusions}

In this work, the performance of individual systems; nanofiltration, photocatalysis, and their combination was successfully investigated and discussed. From the results, it was observed that the preliminary dye wastewater treatment with photocatalysis and secondary treatment with nanofiltration was effective. At catalyst loading of $0.2 \mathrm{~g} / \mathrm{L}$ and $\mathrm{pH} 5.26$, the maximum dye removal was achieved. These are considered as the optimum operating conditions. Also, it was noticed that on increasing the initial dye concentration, the decolorization was decreased. And in the combined system $70 \%$ of TOC was removed in $94.23 \mathrm{~min}$ of operational time. The maximum decolorization was achieved when the experiments were conducted at the obtained optimum values. This can be concluded as the best approach for the effective MB dye decolorization using optimized operating parameters designed in the RSM experimental model. This experiment has utilized lower energy, less time, minimal membrane fouling because of the combined process and also economical. Hence, this study can be termed as successful.

\section{Acknowledgements}

The authors are grateful for the financial support provided by MHRD, Government of India. We would also like to give gracious thanks to the Director, National Institute of Technology Warangal for his support during the research. Authors declare that there is no conflict of Interest.

\section{References}

[1] Lydakis-Simantiris N, Riga D, Katsivela E, et al. Disinfection of spring water and secondary treated municipal wastewater by $\mathrm{TiO} 2$ photocatalysis. Desalination [Internet]. 2010;250:351-355. Available from: 
http://dx.doi.org/10.1016/j.desal.2009.09.055.

[2] Herrmann JM, Duchamp C, Karkmaz M, et al. Environmental green chemistry as defined by photocatalysis. J. Hazard. Mater. 2007;146:624-629.

[3] WU X, SU P, LIU H, et al. Photocatalytic degradation of Rhodamine B under visible light with Nd-doped titanium dioxide films. J. Rare Earths. 2009;27:739-743.

[4] Fujishima A, Zhang X. Titanium dioxide photocatalysis: present situation and future approaches. Comptes Rendus Chim. 2006;9:750-760.

[5] Saikia L, Bhuyan D, Saikia M, et al. Photocatalytic performance of $\mathrm{ZnO}$ nanomaterials for self sensitized degradation of malachite green dye under solar light. Appl. Catal. A Gen. [Internet]. 2015;490:42-49. Available from: http://dx.doi.org/10.1016/j.apcata.2014.10.053.

[6] El-Kemary M, El-Shamy H, El-Mehasseb I. Photocatalytic degradation of ciprofloxacin drug in water using $\mathrm{ZnO}$ nanoparticles. J. Lumin. [Internet]. 2010;130:2327-2331. Available from: http://dx.doi.org/10.1016/j.jlumin.2010.07.013.

[7] Meng F, Chae SR, Drews A, et al. Recent advances in membrane bioreactors (MBRs): Membrane fouling and membrane material. Water Res. [Internet]. 2009;43:1489-1512. Available from: http://dx.doi.org/10.1016/j.watres.2008.12.044.

[8] Liu CX, Zhang DR, He Y, et al. Modification of membrane surface for anti-biofouling performance: Effect of anti-adhesion and anti-bacteria approaches. J. Memb. Sci. 2010;346:121-130.

[9] Zhang X, Wang DK, Lopez DRS, et al. Fabrication of nanostructured TiO2 hollow fiber photocatalytic membrane and application for wastewater treatment. Chem. Eng. J. [Internet]. 2014;236:314-322. Available from: http://dx.doi.org/10.1016/j.cej.2013.09.059.

[10] Pidou M, Parsons SA, Raymond G, et al. Fouling control of a membrane coupled photocatalytic process treating greywater. Water Res. [Internet]. 2009;43:3932-3939. Available from: https://linkinghub.elsevier.com/retrieve/pii/S0043135409003479.

[11] Peng CUI, Xianzhi Z, Minjie Z, et al. Photocatalysis - Membrane Separation Coupling Reactor and Its Application. Chinese J. Catal. 2006;27:752-754.

[12] Lee S-A, Choo K-H, Lee C-H, et al. Use of Ultrafiltration Membranes for the Separation of TiO 2 Photocatalysts in Drinking Water Treatment . Ind. Eng. Chem. Res. 2002;40:1712-1719.

[13] Rajeswari R, Kanmani S. A study on synergistic effect of photocatalytic ozonation for carbaryl degradation. Desalination [Internet]. 2009;242:277-285. Available from: 
http://dx.doi.org/10.1016/j.desal.2008.05.007.

[14] Zahrim AY, Tizaoui C, Hilal N. Coagulation with polymers for nanofiltration pretreatment of highly concentrated dyes: A review. Desalination [Internet]. 2011;266:116. Available from: http://dx.doi.org/10.1016/j.desal.2010.08.012.

[15] Damodar RA, You SJ, Ou SH. Coupling of membrane separation with photocatalytic slurry reactor for advanced dye wastewater treatment. Sep. Purif. Technol. [Internet]. 2010;76:64-71. Available from: http://dx.doi.org/10.1016/j.seppur.2010.09.021.

[16] Grzechulska-Damszel J, Mozia S, Morawski AW. Integration of photocatalysis with membrane processes for purification of water contaminated with organic dyes. Catal. Today [Internet]. 2010;156:295-300. Available from: http://dx.doi.org/10.1016/j.desal.2007.11.084.

[17] Berberidou C, Avlonitis S, Poulios I. Dyestuff effluent treatment by integrated sequential photocatalytic oxidation and membrane filtration. Desalination. 2009;249:1099-1106.

[18] Mozia S. Photocatalytic membrane reactors (PMRs) in water and wastewater treatment. A review. Sep. Purif. Technol. [Internet]. 2010;73:71-91. Available from: http://dx.doi.org/10.1016/j.seppur.2010.03.021.

[19] Strunk J, Kähler K, Xia X, et al. The surface chemistry of ZnO nanoparticles applied as heterogeneous catalysts in methanol synthesis. Surf. Sci. [Internet]. 2009;603:17761783. Available from: http://dx.doi.org/10.1016/j.susc.2008.09.063.

[20] Ullah R, Dutta J. Photocatalytic degradation of organic dyes with manganese-doped ZnO nanoparticles. J. Hazard. Mater. 2008;156:194-200.

[21] Huang J, Xu X, Gu C, et al. Effective VOCs gas sensor based on porous $\mathrm{SnO} 2$ microcubes prepared via spontaneous phase segregation. Sensors Actuators, B Chem. [Internet]. 2012;173:599-606. Available from: http://dx.doi.org/10.1016/j.snb.2012.07.068.

[22] Danwittayakul S, Jaisai M, Dutta J. Efficient solar photocatalytic degradation of textile wastewater using $\mathrm{ZnO} / \mathrm{ZTO}$ composites. Appl. Catal. B Environ. [Internet]. 2015;163:1-8. Available from: http://dx.doi.org/10.1016/j.apcatb.2014.07.042.

[23] Danwittayakul S, Jaisai M, Koottatep T, et al. Enhancement of photocatalytic degradation of methyl orange by supported zinc oxide nanorods/zinc stannate (ZnO/ZTO) on porous substrates. Ind. Eng. Chem. Res. 2013;52:13629-13636.

[24] Ali AM, Emanuelsson EAC, Patterson DA. Photocatalysis with nanostructured zinc oxide thin films: The relationship between morphology and photocatalytic activity 
under oxygen limited and oxygen rich conditions and evidence for a Mars Van Krevelen mechanism. Appl. Catal. B Environ. [Internet]. 2010;97:168-181. Available from: http://dx.doi.org/10.1016/j.apcatb.2010.03.037.

[25] Pardeshi SK, Patil AB. Effect of morphology and crystallite size on solar photocatalytic activity of zinc oxide synthesized by solution free mechanochemical method. J. Mol. Catal. A Chem. 2009;308:32-40.

[26] Kwak JS. Application of Taguchi and response surface methodologies for geometric error in surface grinding process. Int. J. Mach. Tools Manuf. 2005;45:327-334.

[27] Peasura P. Application of Response Surface Methodology for Modeling of Postweld Heat Treatment Process in a Pressure Vessel Steel ASTM A516 Grade 70. Sci. World J. $2015 ; 2015$.

[28] Kasiri MB, Aleboyeh H, Aleboyeh A. Modeling and optimization of heterogeneous photo-fenton process with response surface methodology and artificial neural networks," Environmental Science and Technology, vol. 42, no. 21, pp. 7970- 7975, 2008. 2008;42:7970-7975.

[29] Khataee AR, Fathinia M, Aber S, et al. Optimization of photocatalytic treatment of dye solution on supported $\mathrm{TiO} 2$ nanoparticles by central composite design: Intermediates identification. J. Hazard. Mater. [Internet]. 2010;181:886-897. Available from: http://dx.doi.org/10.1016/j.jhazmat.2010.05.096.

[30] Zhou J, Zhao F, Wang Y, et al. Size-controlled synthesis of ZnO nanoparticles and their photoluminescence properties. J. Lumin. 2007;122-123:195-197.

[31] Khoshhesab ZM, Sarfaraz M, Asadabad MA. Preparation of ZnO nanostructures by chemical precipitation method. Synth. React. Inorganic, Met. Nano-Metal Chem. 2011;41:814-819.

[32] Neppolian B, Choi HC, Sakthivel S, et al. Solar light induced and $\mathrm{TiO} 2$ assisted degradation of textile dye reactive blue 4. Chemosphere. 2002;46:1173-1181.

[33] Lu C, Wu Y, Mai F, et al. Degradation efficiencies and mechanisms of the ZnOmediated photocatalytic degradation of Basic Blue 11 under visible light irradiation. J. Mol. Catal. A Chem. 2009;310:159-165.

[34] Wong Y, Yu J. Laccase-catalyzed decolorization of synthetic dyes. Water Res. 1999;33:3512-3520.

[35] Banat IM, Nigam P, Singh D, et al. Microbial decolorization of textile-dye-containing effluents: A review. Bioresour. Technol. 1996;58:217-227.

[36] Namasivayam C, Dinesh Kumar M, Selvi K, et al. "Waste" coir pith - A potential 
biomass for the treatment of dyeing wastewaters. Biomass and Bioenergy. 2001;21:477-483.

[37] Chatterjee S, Chatterjee S, Chatterjee BP, et al. Adsorption of a model anionic dye, eosin Y, from aqueous solution by chitosan hydrobeads. J. Colloid Interface Sci. 2005;288:30-35.

[38] Evgenidou E, Fytianos K, Poulios I. Semiconductor-sensitized photodegradation of dichlorvos in water using $\mathrm{TiO} 2$ and $\mathrm{ZnO}$ as catalysts. Appl. Catal. B Environ. 2005;59:81-89.

[39] Naresh Yadav D, Anand Kishore K, Bethi B, et al. ZnO nanophotocatalysts coupled with ceramic membrane method for treatment of Rhodamine-B dye waste water. Environ. Dev. Sustain. 2018;20:2065-2078.

[40] Nagaraja R, Kottam N, Girija CR, et al. Photocatalytic degradation of Rhodamine B dye under UV/solar light using $\mathrm{ZnO}$ nanopowder synthesized by solution combustion route. Powder Technol. [Internet]. 2012;215-216:91-97. Available from: http://dx.doi.org/10.1016/j.powtec.2011.09.014.

[41] Akyol A, Yatmaz HC, Bayramoglu M. Photocatalytic decolorization of Remazol Red RR in aqueous ZnO suspensions. Appl. Catal. B Environ. 2004;54:19-24.

[42] Baslak C, Arslan G, Kus M, et al. Removal of Rhodamine B from water by using CdTeSe quantum dot-cellulose membrane composites. RSC Adv. 2016;6:18549_ 18557.

[43] Wang JP, Chen YZ, Ge XW, et al. Optimization of coagulation-flocculation process for a paper-recycling wastewater treatment using response surface methodology. Colloids Surfaces A Physicochem. Eng. Asp. 2007;302:204-210.

[44] Mokhtar NM, Lau WJ, Ismail AF, et al. Performance evaluation of novel PVDFCloisite 15A hollow fiber composite membranes for treatment of effluents containing dyes and salts using membrane distillation. RSC Adv. [Internet]. 2015;5:38011-38020. Available from: http://dx.doi.org/10.1039/C5RA00182J.

[45] Salahi A, Noshadi I, Badrnezhad R, et al. Nano-porous membrane process for oily wastewater treatment: Optimization using response surface methodology. J. Environ. Chem. Eng. [Internet]. 2013;1:218-225. Available from: http://dx.doi.org/10.1016/j.jece.2013.04.021.

[46] Yuliwati E, Ismail AF, Lau WJ, et al. Effects of process conditions in submerged ultrafiltration for refinery wastewater treatment: Optimization of operating process by response surface methodology. Desalination. 2012;287:350-361. 
[47] Ay F, Catalkaya EC, Kargi F. A statistical experiment design approach for advanced oxidation of Direct Red azo-dye by photo-Fenton treatment. J. Hazard. Mater. 2009;162:230-236.

[48] Moradi M, Zinatizadeh AA, Zinadini S. Influence of Operating Variables on Performance of Nanofiltration Membrane for Dye Removal from Synthetic Wastewater Using Response Surface Methodology. Int. J. Eng. 2016;29:1650-1658.

[49] Askari N, Farhadian M, Razmjou A. Simultaneous effects of pH, concentration, pressure on dye removal by a polyamide nanofilter membrane; optimization through response surface methodology. Environ. Nanotechnology, Monit. Manag. [Internet]. 2018;10:223-230. Available from: https://doi.org/10.1016/j.enmm.2018.07.002.

[50] Mortazavian S, Saber A, James DE. Optimization of photocatalytic degradation of acid blue 113 and acid red 88 textile dyes in a uv-c/tio 2 suspension system: Application of response surface methodology (rsm). Catalysts. 2019;9.

[51] Abdullah AH, Moey HJM, Yusof NA. Response surface methodology analysis of the photocatalytic removal of Methylene Blue using bismuth vanadate prepared via polyol route. J. Environ. Sci. (China) [Internet]. 2012;24:1694-1701. Available from: http://dx.doi.org/10.1016/S1001-0742(11)60966-2. 